\section{P5-S4.08 INTEGRATION OF SYPHILIS POINT-OF-CARE TEST INTO OUTREACH INTERVENTION SERVICES AT COMMERCIAL SEX VENUES IN SOUTHERN CHINA}

doi:10.1136/sextrans-2011-050108.549

${ }^{1} Y$ P Yin, ${ }^{1} \mathrm{~J} \mathrm{Li},{ }^{1}$ W H Wei, ${ }^{1} \mathrm{H}$ C Wang, ${ }^{2} \mathrm{R}$ W Peeling, ${ }^{1} \mathrm{X}$ S Chen. ${ }^{1}$ National Center for STD Control and the Chinese Academy of Medical Sciences Institute of Dermatology, Nanjing, China; ' 2 London School of Hygiene and Tropical Medicine, London, UK

Background Introduction of the point-of-care tests (rapid tests) for sexually transmitted infections (STIs) presents an opportunity to expand screening and treatment services in non-clinical settings, such as commercial sex venues where individuals who do not access standard healthcare services can be reached. A free syphilis screening with the rapid test was implemented in two southern Chinese cities (LZ and JM) to assess the feasibility of integrating rapid syphilis testing into existing outreach services for female sex workers (FSWs). Methods Commercial sex venues in the study sites were systematically mapped, and free rapid syphilis testing using whole blood from fingerstick was provided to the target population as a component of routine outreach services at those venues.

Results From April 2009 to February 2010, a total of 2821 FSWs were approached by outreach workers and offered invitation to accept an onsite rapid syphilis testing, $95.1 \%$ of which accepted the test. Test acceptance rate varied a bit across different types of commercial sex venues, ranging from $91.5 \%$ among FSWs working at nightclubs to $97.6 \%$ among those on streets. Most $(99.5 \%)$ preferred immediate onsite results notification or through cellphone rather than receiving it at a designated referral clinic. $182(6.8 \%)$ respondents had a positive result, among whom $63.7 \%$ visited designated referral clinics for confirmatory test and treatment. Test uptake was positively correlated with JM (AOR 2.4, 95\% CI 1.4 to 4.2), age 30-44 years old (AOR 1.9, 95\% CI 1.1 to 3.3), no prior syphilis infection (AOR 2.7, 95\% CI 1.3 to 5.5), or unknown history of syphilis infection (AOR 4.5, 95\% CI 1.5 to 13.3), and negatively associated with working in roadside restaurants (AOR 0.3, 95\% CI 0.1 to 0.9 ) or sauna/bathing centers (AOR $0.5,95 \%$ CI 0.3 to 0.9 ) compared to FSWs working on streets.

Conclusions It concludes that integration of a rapid and onsite syphilis testing into routine outreach services at sex work venues is feasible and well received at the study areas. However, linkage between onsite testing and referral services should be improved with further efforts to maximise the impact of onsite testing.

\section{Health services and policy poster session 5 : Partner Notification \\ P5-S5.01 FACTORS ASSOCIATED WITH STATED WILLINGNESS TO ACCEPT EXPEDITED PARTNER THERAPY FROM SEX PARTNERS, NYC, 2007-2008}

doi:10.1136/sextrans-2011-050108.550

${ }^{1} \mathrm{D}$ Sanchez, ${ }^{1} \mathrm{~K}$ L Ricchetti-Masterson, ${ }^{2} \mathrm{~S}$ Handel, ${ }^{2} \mathrm{M}$ Rogers, ${ }^{2} \mathrm{~J}$ A Schillinger. ${ }^{1}$ University of North Carolina Chapel Hill Gillings School of Global Public Health, Chapel Hill, USA; ${ }^{2}$ New York City Department of Health and Mental Hygiene, New York, USA

Background Expedited Partner Therapy (EPT) is a partner management strategy that relies upon index patients to deliver STD treatment to their sex partners without an evaluation by a healthcare provider. Characterisation of barriers and facilitators of EPT acceptance could inform approaches to EPT implementation. The New York City (NYC) Bureau of STD Control is in the process of implementing EPT and is offering technical assistance on EPT to healthcare providers throughout the city.

Methods During 2007-2008, we used a self-administered survey to assess factors associated with hypothetical willingness to accept EPT from an index patient among adults attending two NYC STD clinics. Binomial regression was used to estimate prevalence ratios (PRs) between select survey items and hypothetical willingness to accept EPT from their most recent sex partner, as measured by the question "If your most recent sex partner brought you medicine to treat an STD, would you take it?"

Results Among 658 respondents, median age was 25 (range 14-68); $338(51.4 \%)$ were male. Almost half (42.7\%) reported willingness to accept EPT from their most recent sex partner. We examined the association between patient sex, history of chlamydia (CT)/gonorrhoea (GC), last sexual partner type, number of sex partners in past 3 months, and age, with willingness to accept EPT from most recent sex partner. Those willing to accept EPT from their most recent sex partner were more likely to be male ( $P R=1.1495 \%$ CI 1.00 to 1.31$)$, more likely to have a history of CT/GC ( $\mathrm{PR}=1.28$; $95 \%$ CI 1.07 to 1.52), and more likely to report $1-2$ sex partners in the past 3 months $(\mathrm{PR}=1.04 ; 95 \% \mathrm{CI} 0.88$ to 1.22 ). Respondents whose most recent sex partner was a steady partner were more likely to accept EPT ( $P R=1.09 ; 95 \%$ CI 0.95 to 1.26). Age was not associated with willingness to accept EPT. Only sex and history of CT/GC were significantly associated with willingness to accept EPT in crude analyses ( $p=0.006$, and $p=0.05$, respectively) see Abstract P5-S5.01 table 1 .

Conclusions Aside from partner's sex, we did not identify any patient characteristics which could be used to predict sex partners' willingness to take medication offered via EPT. Active follow-up with partners given EPT will provide a more direct measure of the acceptability and utilisation of medication delivered to sex partners.

Abstract P5-S5.01 Table 1 Crude associations between select population characteristics and willingness to accept EPT among NYC STD clinic attendees, 2007-2008

\begin{tabular}{|c|c|c|c|c|}
\hline \multirow[b]{2}{*}{ Covariate } & \multicolumn{2}{|c|}{$\begin{array}{l}\text { Willingness to } \\
\text { Accept EPT }\end{array}$} & \multicolumn{2}{|c|}{$\begin{array}{l}\text { Crude Association with } \\
\text { Willingness to Accept EPT }\end{array}$} \\
\hline & Yes (N (\%)) & No (N (\%)) & PR (95\% CI) & p Value \\
\hline \multicolumn{5}{|c|}{ Known history of $\mathrm{CT} / \mathrm{GC}$} \\
\hline No & $167(38.9)$ & $262(61.1)$ & 1 & \\
\hline Yes & $114(49.8)$ & $115(50.2)$ & $1.28(1.07$ to 1.52$)$ & 0.006 \\
\hline \multicolumn{5}{|c|}{ Sex of respondent } \\
\hline Female & $124(38.8)$ & $196(61.3)$ & 1. & \\
\hline Male & $157(46.5)$ & $181(53.6)$ & $1.14(1.00$ to 1.31$)$ & 0.05 \\
\hline \multicolumn{5}{|c|}{ Last sexual partnership type } \\
\hline Casual & $70(38.9)$ & $110(61.1)$ & 1 & \\
\hline Steady & $211(44.1)$ & $267(55.9)$ & $1.09(0.95$ to 1.26$)$ & 0.21 \\
\hline \multicolumn{5}{|c|}{ Number of sex partners in the past three mos ${ }^{*}$} \\
\hline 0 & $15(38.5)$ & $24(61.5)$ & 1 & \\
\hline $1-2$ & $211(42.0)$ & $291(58.0)$ & $1.04(0.88$ to 1.22$)$ & 0.66 \\
\hline $3+$ & $55(47.0)$ & $62(53.0)$ & $1.09(0.91$ to 1.30$)$ & 0.35 \\
\hline \multicolumn{5}{|l|}{ Age (years) } \\
\hline$<20$ & $43(39.5)$ & $66(60.6)$ & 1 & \\
\hline $20-25$ & $96(41.2)$ & $137(58.8)$ & $1.04(0.79$ to 1.40$)$ & 0.76 \\
\hline $26-49$ & $131(46.1)$ & $153(53.9)$ & $1.17(0.90$ to 1.52$)$ & 0.23 \\
\hline $50+$ & $11(34.4)$ & $21(65.6)$ & $0.87(0.51$ to 1.48$)$ & 0.61 \\
\hline
\end{tabular}

\section{P5-S5.02 OUTCOMES FOLLOWING THE INTRODUCTION OF HIV PARTNER NOTIFICATION GUIDELINES IN EDMIONTON, CANADA}

doi:10.1136/sextrans-2011-050108.551

J Bergman, J Brandley, J Gratrix, K Ross, K Paradis, P Parker, B Anderson, S Houston, A Singh. Alberta Health Services, Edmonton, Canada

Background In April 2010, the HIV Partner Notification Guidelines were implemented in Edmonton, Alberta, Canada. Prior to this, partner notification of newly diagnosed HIV cases was conducted inconsistently. 
Methods All individuals newly diagnosed with HIV in the Alberta Health Services- Edmonton zone were interviewed by a partner notification nurse (PNN) for sexual and needle sharing partners, and perinatal contacts under Alberta's Public Health Act. PNNs attempted to locate named contacts to ensure timely counselling, testing, and follow-up care. The number of contacts in the year preceding the diagnosis and information required to locate each contact was recorded for each case. Additional information included whether they were located, tested, and their test results; all information was entered into a Notifiable Disease Reporting database. A descriptive analysis was performed on the characteristics and outcomes of data collected between 5 April and 31 December 2010. Results There were 50 newly diagnosed HIV cases during this time period. The majority $(n=33 ; 66 \%)$ of the cases were male and the overall median age was 39 years (IOR 32-48). Male cases were more likely to be Caucasian $(\mathrm{n}=21 ; 63.6 \%)$ while female cases were more likely to be Aboriginal ( $n=8 ; 47.1 \%, p=0.001)$. The primary mode of transmission among male cases was MSM ( $n=18 ; 54.5 \%)$ and among female cases was heterosexual transmission ( $n=10 ; 58.8 \%)$. A total of 92 contacts were provided by 36 (72\%) of the HIV cases, with an average of 2.6 (range 1-14) contacts per case. The majority $(97.8 \% ; n=90)$ of contacts were exposed through sex with an additional $5(5.4 \%)$ contacts being exposed through needle sharing during drug use. Of the 92 named contacts, $17.4 \% \quad(n=16)$ were found to be previously positive for HIV, 16.3\% ( $n=15)$ resided outside of Edmonton, and the remaining $66.3 \% \quad(n=61)$ were followed up by local PNNs. At the time of analysis, $75.4 \%(n=45)$ of the contacts were located and of those located, $82.6 \%(n=38)$ were tested resulting in four new cases of HIV.

Conclusions HIV partner notification efforts resulted in the majority of contacts being located and tested for HIV, with four new cases of HIV identified. Nearly one-quarter $(n=20 ; 21.7 \%)$ of the total contacts were HIV positive, suggesting a need for ongoing prevention and risk reduction strategies for individuals living with HIV and their partners.

\section{P5-S5.03 PARTNER NOTIFICATION AND TREATMENT FOR MATERNAL SYPHILIS IN LIMA, PERU: KNOWLEDGE, ATTITUDES, AND PRACTICES OF HEALTH PROVIDERS AND PATIENTS}

\section{doi:10.1136/sextrans-2011-050108.552}

${ }^{1} \mathrm{~B}$ Williams, ${ }^{2} \mathrm{P}$ Garcia, ${ }^{2} \mathrm{C}$ Carcamo, ${ }^{2} \mathrm{M}$ Chiape Guiterrez, ${ }^{2} \mathrm{~S}$ De la Rosa Roca, ${ }^{2} \mathrm{M}$ V Calderon, ${ }^{3} \mathrm{R}$ Peeling. ${ }^{1}$ Columbia University Mailman School of Public Health, New York, USA; ${ }^{2}$ Universidad Peruana Cayetano Heredia, Peru; London School of Hygiene and Tropical Medicine, UK

We sought to identify factors that affect partner notification and treatment for maternal syphilis as part of an implementation research study on the feasibility of using rapid syphilis testing (RST) in reproductive health services in Lima, Peru. Congenital syphilis remains a significant problem in many regions of the world. Prevention depends on successful treatment of syphilis-positive pregnant women. Treatment of sexual partners is essential to prevent re-infection. We conducted exploratory research to identify factors that contributed to poor rates of partner treatment after month 3 of RST implementation. Quantitative data collected from 127 RST-positive pregnant women was used to identify patient factors associated with partner treatment. A subset of 18 women participated in qualitative interviews. Fifty-eight health providers completed a survey of knowledge, attitudes, and practices related to counselling and treatment of syphilis-positive women and partners. National guidelines for follow-up and treatment of syphilis were also reviewed. Providers reported lack of human resources and coordination as reasons for failure to perform follow-up of partners. $33(56.9 \%)$ providers said they were not well prepared for counselling and would like additional training. Providers relayed strategies they used to treat partners, and reported paying greater attention to follow-up of partners and documentation of partner treatment since RST introduction. Fear of blame, violence, and abandonment were cited as reasons why women were less likely to notify a partner, while distrust in test results, "machismo", and lack of knowledge were said to make partners less likely to seek treatment. Women interviewed who had notified partners of their diagnosis reported that notification was easier when a health provider was present. No women reported violent responses from their partners after notifying. Reasons women said that partners had not received treatment included difficulty seeking care during regular clinic hours and lack of knowledge. In bivariate analysis only marital status was found to predict whether or not partners received treatment $(p=0.004)$ see Abstract P5-S5.03 table 1. Data collected from patients and providers showed that women were aware of the importance of partner notification, but male partners often did not seek treatment due to systemic barriers. Health systems should prioritise partner-friendly treatment strategies. National guidelines need to clearly define procedures for partner follow-up.

Abstract P5-S5.03 Table 1 RST-Positive Pregnant Women (1 February-15 November 2010) and first dose of partner treatment: logistic regression

\begin{tabular}{|c|c|c|c|c|}
\hline Variable & $\begin{array}{l}\text { Partner } \\
\text { treated, } \\
\mathrm{n}(\%)\end{array}$ & $\begin{array}{l}\text { Partner not } \\
\text { treated, } \\
\text { n (\%) }\end{array}$ & $\begin{array}{l}p \\
\text { Value }\end{array}$ & $\begin{array}{l}\text { OR } \\
(95 \% \mathrm{Cl})\end{array}$ \\
\hline Age $(n=127)$ & & & 0.245 & \\
\hline $\begin{array}{l}\text { Health establishment } \\
(\mathrm{n}=127)\end{array}$ & & & 0.56 & \\
\hline INMP $(n=90)$ & $46(51.1)$ & $44(48.9)$ & & 1.0 \\
\hline Ventanilla-Callao $(n=37)$ & $21(56.8)$ & $16(43.2)$ & & 1.26 (0.58 to 2.71$)$ \\
\hline Marital Status $(n=127)$ & & & 0.004 & \\
\hline $\begin{array}{l}\text { Single or separated } \\
(n=22)\end{array}$ & $5(22.7)$ & $17(77.3)$ & & 1.0 \\
\hline $\begin{array}{l}\text { Married or living } \\
\text { together }(n=105)\end{array}$ & $69(65.7)$ & $36(34.3)$ & & 4.9 (1.68 to 14.30$)$ \\
\hline Education $(n=126)$ & & & 0.81 & \\
\hline $\begin{array}{l}\text { No education/primary } \\
\text { school }(\mathrm{n}=22)\end{array}$ & $11(50.0)$ & $11(50.0)$ & & 1.0 \\
\hline $\begin{array}{l}\text { Secondary school /university } \\
\text { degree }(n=104)\end{array}$ & $55(52.9)$ & $49(47.1)$ & & 1.12 (0.45 to 2.82$)$ \\
\hline $\begin{array}{l}\text { Antenatal visit prior to } \\
\text { syphilis diagnosis? }(\mathrm{n}=127)\end{array}$ & & & 0.45 & \\
\hline Yes $(n=51)$ & $29(56.9)$ & $22(43.1)$ & & 1.0 \\
\hline No $(n=76)$ & $38(50.0)$ & $38(50.0$ & & $1.32(0.65$ to 2.70$)$ \\
\hline $\begin{array}{l}\text { No. of antenatal visits } \\
\text { prior to diagnosis }(n=127)\end{array}$ & & & 0.84 & $1.04(0.73$ to 1.48$)$ \\
\hline $\begin{array}{l}\text { No. of sexual partners } \\
\text { ever }(n=125)\end{array}$ & & & 0.56 & $0.93(0.72$ to 1.20$)$ \\
\hline
\end{tabular}

\section{P5-S5.04 PROVIDER AND CONTRACT REFERRAL FOR BACTERIAL STIS: TWO SIDES OF THE SAME COIN?}

doi:10.1136/sextrans-2011-050108.553

${ }^{1} \mathrm{~J}$ Cassell, ${ }^{2} \mathrm{C}$ Estcourt, ${ }^{2} \mathrm{M}$ Symonds, ${ }^{3} \mathrm{~J}$ Richens, ${ }^{3} \mathrm{G}$ Rait, ${ }^{1} \mathrm{~S}$ Lanza, ${ }^{4} \mathrm{~J}$ Dodds, ${ }^{1} \mathrm{H}$ Smith. ${ }^{1}$ Brighton and Sussex Medical School, Brighton, UK; ${ }^{2}$ Queen Mary, University of London, UK; ${ }^{3}$ University College London, UK; ${ }^{4}$ MRC General Practice Research Framework, UK

Background During the pilot of an RCT of provider, contract and patient referral, for a 66 practice RCT of partner notification in UK primary care, it emerged that there is uncertainty about real life clinical practice. Our objectives are to describe how health advisers negotiate provider, contract and patient partner notification in clinical practice. To determine the feasibility of 